\title{
An additional specimen of owenettid procolophonoid from the Middle Triassic of Southern Brazil
}

\author{
Rodrigo T. Müller \\ Acta Palaeontologica Polonica 66 (4), 2021: 827-836 doi:https://doi.org/10.4202/app.00909.2021
}

Owenettids are small procolophonoids that survived beyond the Permo-Triassic boundary. The fossil record of owenettids range from the upper Permian to the Middle Triassic. These records come from South Africa, Madagascar, Tanzania, Germany, and Brazil. Despite its conservative anatomy, some species depict some peculiar traits, such as Candelaria barbouri. This owenettid comes from Middle Triassic of Brazil and is characterized by the presence of temporal openings, a highly unusual trait in procolophonoids. Here, a new specimen of $C$. barbouri is described. The specimen comes from the "Posto" site, an iconic fossiliferous locality from southern Brazil. The material is assigned to $C$. barbouri based on the presence of temporal openings. In addition, its owenettid affinities are supported by two phylogenetic analyses. The new specimen is the first parareptile from the "Posto" site, providing further data for biostratigraphic hypotheses. Finally, a morphological disparity analysis reveals no overlapped areas between the morphospace occupied by procolophonids and owenettids, reinforcing the existence of these two distinct groups. Furthermore, the morphospace area occupied by owenettids is far reduced in comparison to that of procolophonids, reflecting the conservative anatomy of owenettids.

Key words: Parareptilia, Procolophonia, Owenettidae, Candelaria barbouri, phylogeny, Ladinian, Santa Maria Formation, South America.

Rodrigo T. Müller [rodrigotmuller@ hotmail.com], Centro de Apoio à Pesquisa Paleontológica da Quarta Colônia, Universidade Federal de Santa Maria, São João do Polêsine, RS 598, 97230-000, Brazil. Programa de Pós-Graduação em Biodiversidade Animal, Universidade Federal de Santa Maria, 97105-120, Santa Maria, Rio Grande do Sul, Brazil

This is an open-access article distributed under the terms of the Creative Commons Attribution License (for details please see creativecommons.org), which permits unrestricted use, distribution, and reproduction in any medium, provided the original author and source are credited. 
Fog 2 Full text $(1,211.7 \mathrm{kB})$ ।

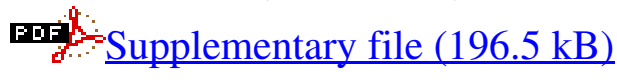

